\title{
A Compact Triple Band EBG Using Interdigital Coplanar Waveguide Structure for Antenna Gain Enhancement
}

\author{
Prapoch Jirasakulporn (D), ${ }^{1}$ Pongsathorn Chomtong $\mathbb{D D}^{2}$ Kamorn Bandudej, ${ }^{3}$ \\ and Prayoot Akkaraekthalin ${ }^{1}$ \\ ${ }^{1}$ Department of Electrical and Computer Engineering, King Mongkut's University of Technology North Bangkok, \\ Pracharat 1 Road, Angsue, Bangkok 1518, Thailand \\ ${ }^{2}$ Department of Teacher Training in Electrical Engineering, Faculty of Technical Education, \\ King Mongkut's University of Technology North Bangkok, Pracharat 1 Road, Angsue, Bangkok 1518, Thailand \\ ${ }^{3}$ National Astronomical Research Institute of Thailand (NARIT), Princess Sirindhorn Astro Park, 260 Moo 4, Donkaew, Maerim, \\ Chiangmai, Thailand
}

Correspondence should be addressed to Pongsathorn Chomtong; tonkmutnb@hotmail.com

Received 6 August 2020; Revised 6 October 2020; Accepted 21 November 2020; Published 11 December 2020

Academic Editor: Seong-Youp Suh

Copyright (C) 2020 Prapoch Jirasakulporn et al. This is an open access article distributed under the Creative Commons Attribution License, which permits unrestricted use, distribution, and reproduction in any medium, provided the original work is properly cited.

\begin{abstract}
A new triple band EBG unit cell with compact size has been designed, fabricated, and tested. The proposed EBG unit cell is based on a square mushroom-like EBG (M-EBG) structure with an interdigital coplanar waveguide (ICPW). With this technique, the size of the proposed ICPW-EBG structure has been reduced from $\lambda / 2$ to $\lambda / 4$ compared with the conventional M-EBG unit cell dimension, which is $18 \times 18 \mathrm{~mm}^{2}$. The proposed unit cell was designed in order to respond for three frequency bands at $1.8 \mathrm{GHz}, 2.45 \mathrm{GHz}$, and 3.7 GHz. An array of $10 \times 10$ unit cell was also designed as a reflector with an overall dimension of $181.8 \times 181.8 \mathrm{~mm}^{2}$. The dipole antennas were implemented over the designed reflector with a short distance of $\lambda / 8$ to radiate electromagnetic wave. The simulation results showed that the ICPW-EBG reflector can improve directivity of the dipole antenna to be $9.12 \mathrm{~dB}$ at $1.8 \mathrm{GHz}, 9.02 \mathrm{~dB}$ at $2.45 \mathrm{GHz}$, and $8.40 \mathrm{~dB}$ at $3.7 \mathrm{GHz}$. The measurement directivities agreed well with simulation results including $8.72 \mathrm{~dB}$ at $1.8 \mathrm{GHz}$, $8.56 \mathrm{~dB}$ at $2.4 \mathrm{GHz}$, and $8.1 \mathrm{~dB}$ at $3.7 \mathrm{GHz}$. This is the first design of triple band EBG unit cell with $50 \%$ size reduction compared with the conventional structure at the same frequency. The designed ICPW-EBG reflector with dipole antenna results in the triple band operation, low-profile and high gain suitable for modern wireless communication systems.
\end{abstract}

\section{Introduction}

Development and design of telecommunication equipment in this modern era must respond to the need of users. Most mobile equipment must be designed for use of multifrequency bands including LTE, WLAN, WiMax, and Bluetooth. Likewise, an antenna, one of the major communication equipment, needs not only to operate for multiple frequencies but also to have low profile, compact size, and high gain. However, design of an antenna having all these features is very complex. There are many techniques to design an antenna to operate with multifrequency band, low profile, small size, and high gain. One of the popular techniques is to design the antenna with artificial material, which is not found in nature, called metamaterial having negative refractive index property, or left-hand material (LHM), theoretically discussed by V.G. Veselago in 1968 [1]. LHM has negative refractive index corresponding to negative relative dielectric permittivity and negative relative magnetic permeability values. The permittivity and permeability characteristics are the macroscopic responses of homogeneous medium when applying electromagnetic fields [2]. LHMs can be applied with electromagnetic devices in microwave and terahertz frequency bands such as antenna, balun, transmission line, and coupler component [3]. Especially, with the negative refractive index of LHMs, the antenna can improve their characteristics of antenna gain, wideband, and multiband [4]. The LHMs are divided into 
electromagnetic bandgap (EBG), single-negative (SNG), double-negative (DNG) materials, etc. [5]. From three types of LHMs, EBG can be designed on a variety of structures when applying to an antenna, resulting in low profile, improved directivity, and wideband operation [6-8]. EBG can be classified into three groups conforming to its geometric configuration: (1) one-dimension transmission lines, (2) two-dimension planar surface, and (3) three-dimension volumetric structures. Using the second geometry, the mushroom-like EBG (M-EBG) is commonly used due to uncomplicated structure and ease of analysis and design for several applications [9]. The M-EBG structure is composed of a patch, via hold, substrate, and ground plane. It has two superior characteristics of surface wave suppression and inphase plane-wave reflection [10].

In the published research study of EBG applied to improve antenna characteristics [11], the comparative analysis of 3 different types of planar EBG was presented. The first one is EBG fractal structure using a simple square patch of $10 \mathrm{~mm}$, resulting in a band gap from $8 \mathrm{GHz}$ to $15 \mathrm{GHz}$. The second is fork type of square patch $10 \mathrm{~mm}$ with a band gap from $7.7 \mathrm{GHz}$ to $15 \mathrm{GHz}$. The third is spiral-shaped EBG with square patch of $10 \mathrm{~mm}$ dimension, which does not respond to $-10 \mathrm{~dB}$ band gap. The number of unit cells in an array was also studied. It was found that increasing the number of unit cells could increase the band gap range to the lower frequency region. It was also concluded that the fork type structure gives better performances with a wider band gap. However, all structures of unit cells have large sizes of about $\lambda / 2$ and it could not independently control the harmonic frequency bands. The second published research study in [12] proposed the uniplanar compact EBG (UC-EBG) and UC-EBG incorporated with interdigital structure called ID-UC-EBG, both having square patch EBG dimensions equal to $7.3 \mathrm{~mm}$. Even though the fringe capacitances on the proposed EBG structures could compress the unit cell sizes to less than $\lambda / 2$, they are still large. Also, the harmonic frequency bands could not be controlled and the structures with two layers are very complicated. In [13], the novel design of two triple band EBGs was presented. The first type is the double slotted type EBG (DSTEBG), in which the microstrip unit cell size is larger compared to the conventional one. It is found that the stop band shifts to the lower frequency side due to increase of capacitance. The gap between the EBG unit cells results in the stop band shifted to the higher frequency. The proposed DSTEBG can operate in three bands with the first band of $2.42-2.95 \mathrm{GHz}$, the second band of $5.82-6.30 \mathrm{GHz}$, and the third band of $8.72-9.28 \mathrm{GHz}$. The second type is triple side slotted EBG (TSSEBG), in which the slot width is increased, resulting in the second and third bands shifting towards the side of lower frequency due to increase of inductance. The proposed TSSEBG can operate with the first band of $4.29-4.65 \mathrm{GHz}$, the second band of $5.56-6.28 \mathrm{GHz}$, and the third band of 7.60-7.94 GHz. Even though the proposed EBG can control three frequency bands when increasing the gap between EBG unit cells, the size is still large.

Normally, the EBG unit cells are designed on the microstrip structure and analyzed by using a circuit model of the transmission line to obtain cell size at the desired resonant frequency [14]. However, the research in [15-17] used coplanar waveguide (CPW) structure to design EBG unit cells because of advantages like low dispersion, small size, and simple realization due to etching on one side and broadband performance [18]. For further size reduction, several techniques have been proposed such as uniplanar compact electromagnetic band gap (UC-EBG), slot-strip EBG structure, interdigital structure, and Hilbert curve structure [19-21]. To design the EBG structure, the interdigital technique is very pliable and effective for size reduction. The interdigital structure can increase capacitance value and decrease quality factor causing the compact sizes [22-26]. From the drawbacks of all research studies mentioned above, this research proposes a design of the new compact EBG unit cell, capable of controlling three frequency bands, modified from the M-EBG unit cell. The coplanar waveguide structure and interdigital technique have been employed to create the EBG for size reduction due to slow wave structure $[27,28]$ and low profile with high gain antenna $[29,30]$. This new EBG is called the interdigital coplanar waveguide electromagnetic bandgap (ICPW-EBG). After that, the ICPW-EBG array is also designed to be a reflector used with dipole antennas for improved directivity at triple band frequency applied for LTE, WLAN, and WiMax [31].

\section{Design of ICPW-EBG and Applications}

The triple band ICPW-EBG reflector consists of two parts including EBG unit cell and array of unit cells. To design the triple band EBG unit cell, the interdigital coplanar waveguide structure is applied on the patch of M-EBG for minimizing size and controlling the resonance frequency as desired. The second part of the design is the ICPW-EBG array being used as an antenna reflector. The ICPW-EBG structure is qualified for disposal of surface wave on the surface of reflector, having only plane wave propagation reinforced with the propagation pattern of the source antenna. With the in-phase plane-wave reflection, the EBG reflector results in a low profile antenna. In this section, the triple band ICPW-EBG unit cell will be designed for LTE (1.8 GHz), WLAN (2.45 GHz), and WiMax (3.7 GHz) [31]. It is designed on FR-4 PCB with $\varepsilon_{r}$ of 4.4, loss tangent of 0.03, and substrate height of $1.6 \mathrm{~mm}$ with CST studio program. Then the ICPW-EBG array as a reflector will be implemented and applied for dipole antennas.

2.1. Triple Band ICPW-EBG Unit Cell. This section proposes the design of the compact triple band EBG unit cell. From the advantages of CPW structure, it was applied on a square patch of M-EBG, due to connectivity of the capacitor at the end of the proposed structure causing slow wave effect [27]. The CPW structure used in this design has a ground plane at bottom and semi grounds on top and operates in odd mode. In Figure $1, C_{i}$ is the capacitance between transmission line and semi ground, $C_{i}^{\prime}$ is the capacitance when the electrical field exists only in a dielectric layer and may be found from the corresponding couple strip line geometry, $C_{g}$ is the 

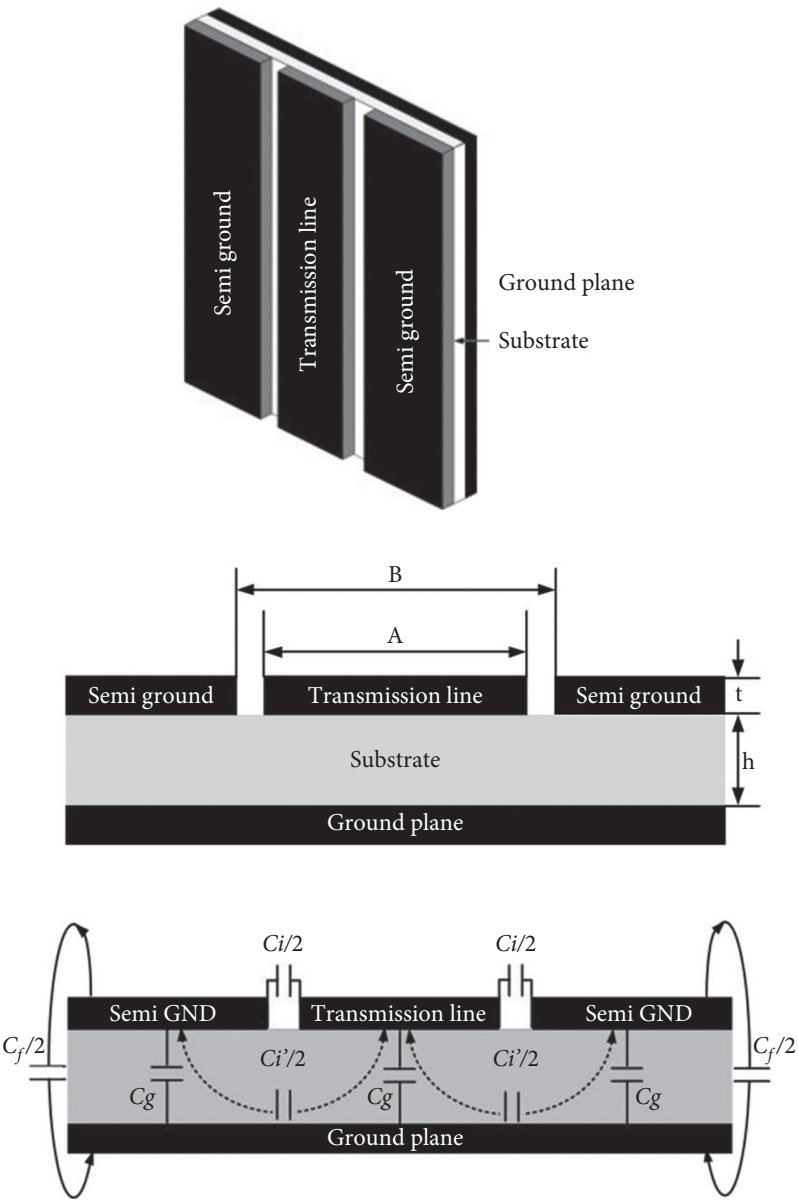

Figure 1: Structure of CPW with ground plane and all capacitive effects.

parallel plate capacitance between semi ground and transmission line to ground plane, and $C_{f}$ is the fringe capacitance. Normally, the values of $C_{i}^{\prime}$ and $C_{f}$ have very small impact on the design to achieve the fundamental frequency resonance. The total capacitance of $\mathrm{CPW}\left(C_{\mathrm{CPW}}\right)$ is very important and its value can be written in (1), where $C$ is the speed of light, $A$ is the width of transmission line, $B$ is the width of transmission line to semi ground, and $C_{Z t}$ is the capacitance of the transmission line:

$$
C_{\mathrm{CPW}}=C_{i}+C_{i}^{\prime}+C_{g}+C_{f},
$$

when

$$
\begin{aligned}
C_{g} & =\varepsilon_{o} \varepsilon_{r} \frac{A}{h}, \\
C_{f} & =\frac{\sqrt{\varepsilon_{r}}}{\left(C_{Z t}\right)-C_{g}}, \\
C_{i}^{\prime} & =\frac{\varepsilon_{o} \varepsilon_{r}}{\pi} \ln \left[\cot h\left(\frac{\pi}{4} \frac{B}{h}\right)\right]+0.65 c_{f}\left(\frac{0.02 \sqrt{\varepsilon_{r}}}{B / h}+1-\frac{1}{\varepsilon_{o}^{2}}\right) .
\end{aligned}
$$

From the basic structure of CPW with ground plane, it is found that the capacitance between transmission line and semi ground $\left(C_{i}\right)$ has more effect on the resonance frequencies. In order to control the second and third harmonic frequencies, the value of $C_{i}$ must be varied instead of $C_{g}$ because it is easier. Then, the interdigital technique has been applied together with CPW to increase $C_{i}$ as the proposed structure shown in Figure 2. It can be seen that there is a finger between the transmission line and the semi ground. The gap and the impedance of the finger between both sides will cause a significant increase in $C_{i}$. Considering the equivalence circuit in Figure 2, the transmission line is divided into three parts composed of $Z_{a}, Z_{b}$, and $Z_{c}$, corresponding to the propagation constants $\beta_{a}, \beta_{b}$, and $\beta_{c}$. From interdigital techniques, the inductance $\left(j X_{L}\right)$ is less than the capacitance $\left(-j X_{C}\right)$, so the $C_{t}=C_{i}+C_{g}$ has a significant effect on the transmission line. $R_{1}$ and $R_{2}$ are the losses in transmission line. In the case of $Z_{a}=Z_{b}=Z_{c}$, the total impedance $\left(Z_{t}\right)$ can be found in (3), where $R$ is the ratio of unequal impedance in transmission line. The admittance $Y_{a}$ can be written as in (4). 


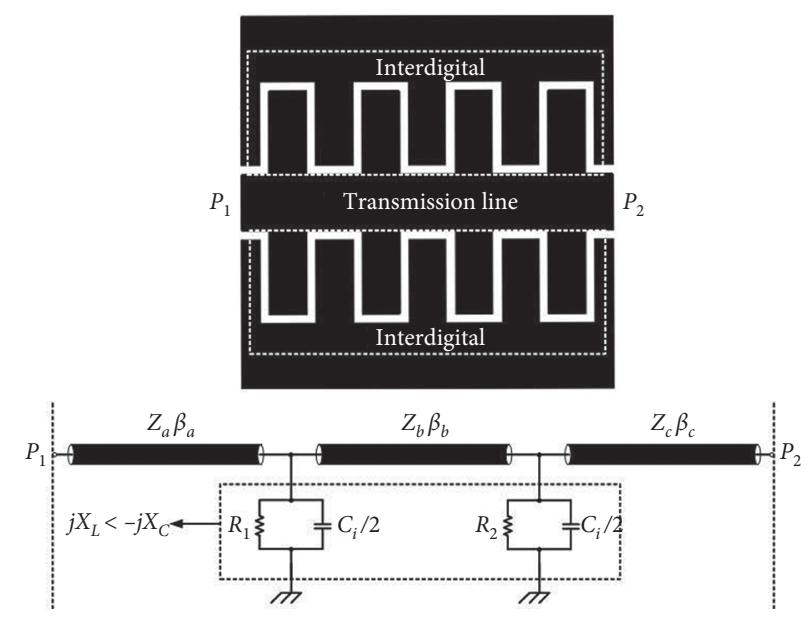

Figure 2: The equivalence circuit of ICPW-EBG unit cell.

$$
Z_{t}=\frac{60 \pi}{\sqrt{\varepsilon_{\text {eff }}}} \frac{1}{\left(K(k) / K\left(k^{\prime}\right)\right)+\left(K\left(k_{x}\right) / K\left(k_{x}^{\prime}\right)\right)},
$$

when

$$
\begin{aligned}
k & =\frac{A}{B}, \\
k^{\prime} & =\sqrt{1.0-k^{2}}, \\
k_{x} & =\frac{\tanh (\pi A / 2 h)}{\tanh ((\pi B / 2) h)}, \\
k_{x}^{\prime} & =\sqrt{1.0-k_{x}^{2}}, \\
\beta & =\frac{2 \pi}{\lambda}, \\
\varepsilon_{\mathrm{eff}} & =\left[\frac{1.0+\varepsilon_{r}\left(\left(K\left(k^{\prime}\right) K(k)\right) /\left(K\left(k_{x}\right) K\left(k_{x}^{\prime}\right)\right)\right)}{1.0+\left(\left(K\left(k^{\prime}\right) K(k)\right) /\left(K\left(k_{x}^{\prime}\right) K\left(k_{x}\right)\right)\right)}\right] \\
Y_{a} & =\frac{1}{Z_{t}}=j Y_{2} \frac{2(1+R)\left(R-\tan ^{2} \theta\right) \tan \theta}{k-2\left(1+R+R^{2}\right) \tan ^{2} \theta+R \tan ^{4} \theta} .
\end{aligned}
$$

From the interdigital connection with CPW transmission line, whether the impedance is equal to the step impedance, the $C_{t}$ is connected to the end of transmission line. It has a significant impact on the electrical lengths of transmission line, as shown in (5) and (6), when $L_{t}$ is the total length of the interdigital part, $L_{f}$ is the length of the finger, and $n$ is the number of fingers. The $C_{t}$ has a very significant effect on the electrical length of the fundamental frequency $\left(f_{0}\right)$ and the third resonance $\left(f_{2}\right)$, while the second resonance $\left(f_{1}\right)$ will have a little effect on electrical length.

$$
\begin{aligned}
& \theta_{a 0}=2 \tan ^{-1}\left(\frac{1}{\pi f_{0} Z_{t} c_{t}}\right) \\
& \theta_{a 1}=2 \pi-2 \tan ^{-1}\left(\pi f_{1} Z_{t} c_{t}\right), \\
& \theta_{a 2}=2 \tan ^{-1}\left(\frac{1}{\pi f_{2} Z_{t} c_{t}}\right), \\
& C_{i}=\frac{\left(\varepsilon_{r}+1\right)}{L_{t}} L_{f}\left(\varepsilon_{r}+1\right)[0.1(n-3)+0.11]
\end{aligned}
$$

when $\eta_{o}=\sqrt{\left(\mu_{o} / \varepsilon_{o}\right)}, k=\left(Z_{2} / Z_{1}\right), L_{p}=\mu_{0} \mu_{r} h$,

$$
C_{a}=\frac{W \varepsilon_{0}\left(1+\varepsilon_{r}\right)}{\pi} \cosh h^{-1}\left(\frac{a}{g}\right) \text {. }
$$

It can be explained that $C_{t}$ value can control the fundamental and third resonance frequencies, while the combination of $C_{t}$ and step-impedance transmission line section can control the second resonance frequency. Furthermore, increasing capacitive value at the end of transmission line with interdigital technique leads to slow wave at transmission line, resulting in unit cell size reduction from $\lambda / 2$ to $\lambda / 4$. Based on the ICPW design, the next step is to design a pin on the ICPW structure. Location and size of the pin were optimized. When arranging two unit cells as shown in Figure 3(a), the capacitive $\left(C_{a}\right)$ is found and the inductance $\left(L_{p}\right)$ arises due to the pins and ground plane. The equivalence circuit of the ICPW-EBG unit cell is shown in Figure $3(\mathrm{~b})$. The values of $L_{p}$ and $C_{a}$ are used to calculate the bandwidth according to (7) and (8). When $a$ is the unit cell range with gap $g$ being the gap width, $W$ is the unit cell width, $h$ is the thickness of substrate, and $\eta_{0}$ is the free space impedance. Therefore, the design equation is changed from (5) to (9) that adds $C_{a}$ into this equation. It is concluded that $C_{a}$ has been taken into account resulting in the change of electrical lengths as shown in (9) and that $C_{t}$ and $C_{a}$ have more effect on the resonance frequencies of the ICPW-EBG unit cell as mentioned. 

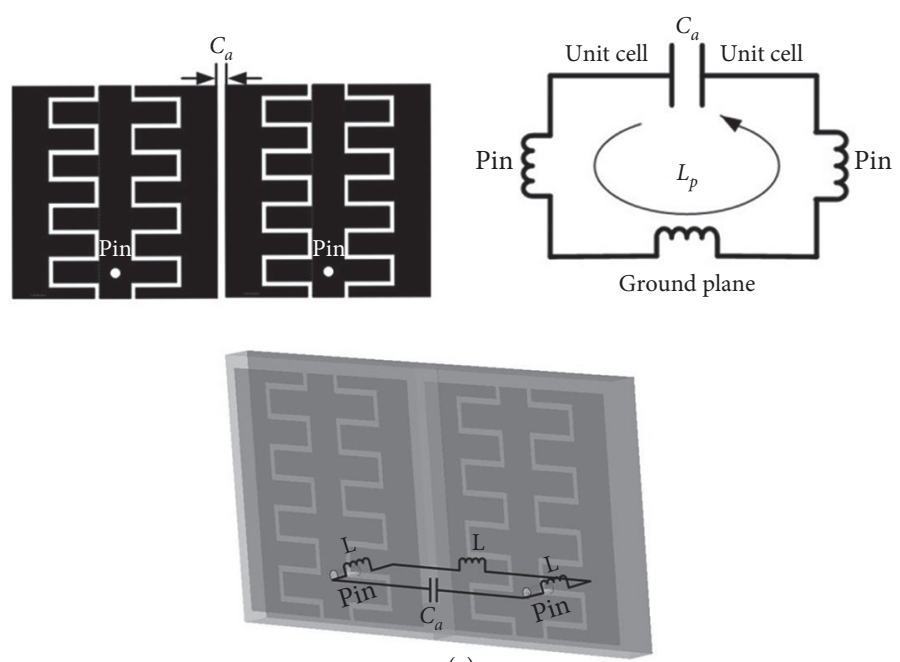

(a)

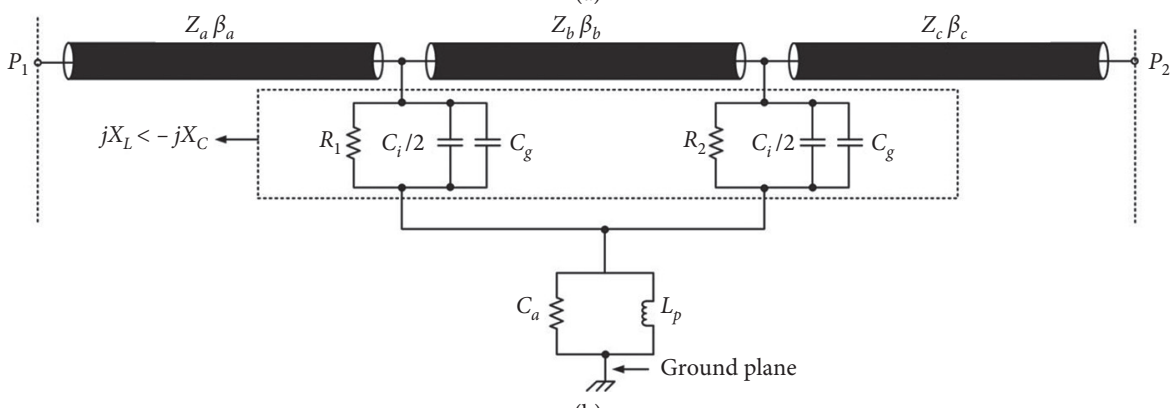

(b)

FIgUre 3: (a) The structure of ICPW-EBG unit cell and capacitance in array EBG. (b) Equivalence circuit of ICPW-EBG unit cell.

The capacitance causes a narrow bandwidth at the resonance frequency. To cover the required bandwidth of the resonance frequency with phase angle of 0 to 90 degrees, one technique commonly used is to increase the substrate thickness. In our design, the FR-4 substrate was employed. The design will determine the transmission line of the ICPW-EBG unit cell with $50 \mathrm{ohm}$ impedance and phase of 0-90 degrees at the fundamental frequency of $1.8 \mathrm{GHz}$. The phases at the second and third resonance frequencies of $2.45 \mathrm{GHz}$ and $3.7 \mathrm{GHz}$ can be controlled by varying the capacitance with interdigital technique. The structure and dimension of the proposed unit cell are shown in Figure 4 and Table 1. To get the required bandwidth, the resonance frequencies must be shifted to $1.94 \mathrm{GHz}, 3.2 \mathrm{GHz}$, and $4.4 \mathrm{GHz}$, respectively. Figure 5 shows the simulation results of phase diagram. The $\mathrm{S}$ curve covers the bandwidth with phase of 0-90 degrees for all frequency bands including $1.66 \mathrm{GHz}-1.92 \mathrm{GHz}$ for $1.8 \mathrm{GHz}$ band, $2.16 \mathrm{GHz}-2.97 \mathrm{GHz}$ for $2.45 \mathrm{GHz}$ band, and $3.43 \mathrm{GHz}-3.98 \mathrm{GHz}$ for $3.7 \mathrm{GHz}$. The simulation of dispersion diagram is also shown in Figure 6. It can be seen that the bandgap had the lower band frequency at frequency of $1.71 \mathrm{GHz}$, the upper band frequency at $3.75 \mathrm{GHz}$, and the center band frequency at $2.73 \mathrm{GHz}$, covering the designed operating frequency. In addition, the size of ICPW unit cell is reduced from $\lambda / 2$ to $\lambda / 4$ by the slow wave effect within the structure. Figure 7 shows the comparison of dimension of ICPW-EBG unit cell and ordinary M-EBG unit cell at the same frequency of $1.8 \mathrm{GHz}$.

$$
\begin{aligned}
\mathrm{BW} & =\frac{1}{\eta_{0}} \sqrt{\frac{L}{C}} \\
\theta_{a o} & =2 \tan ^{-1}\left(\frac{1}{\pi f_{0} Z_{a}\left(C_{t}+C_{a}\right)}\right), \\
\theta_{a 1} & =2 \pi-2 \tan ^{-1}\left(\pi f_{1} Z_{a}\left(C_{t}+C_{a}\right)\right), \\
\theta_{a 2} & =2 \tan ^{-1}\left(\frac{1}{\pi f_{2} Z_{a}\left(C_{t}+C_{a}\right)}\right) .
\end{aligned}
$$

The simulations of E-field and H-field on the ICPW-EBG structure were performed. The results will be used for alignment of the antenna plane corresponding with the ICPW-EBG array plane for maximum efficiency. The simulation results are shown in Figures 8(a) and 8(b), where the E-field has significant impact on the interdigital section of structure at all resonance frequencies, while the $\mathrm{H}$-field has very small impact. Therefore, the antenna must be placed on $Y$-axis or parallel with the interdigital period. Based on the simulation result in Figure 9, there is no current density on the patch of ICPW-EBG unit cell. This means that the ICPW-EBG structure has only plane wave propagation and eliminates surface wave. 

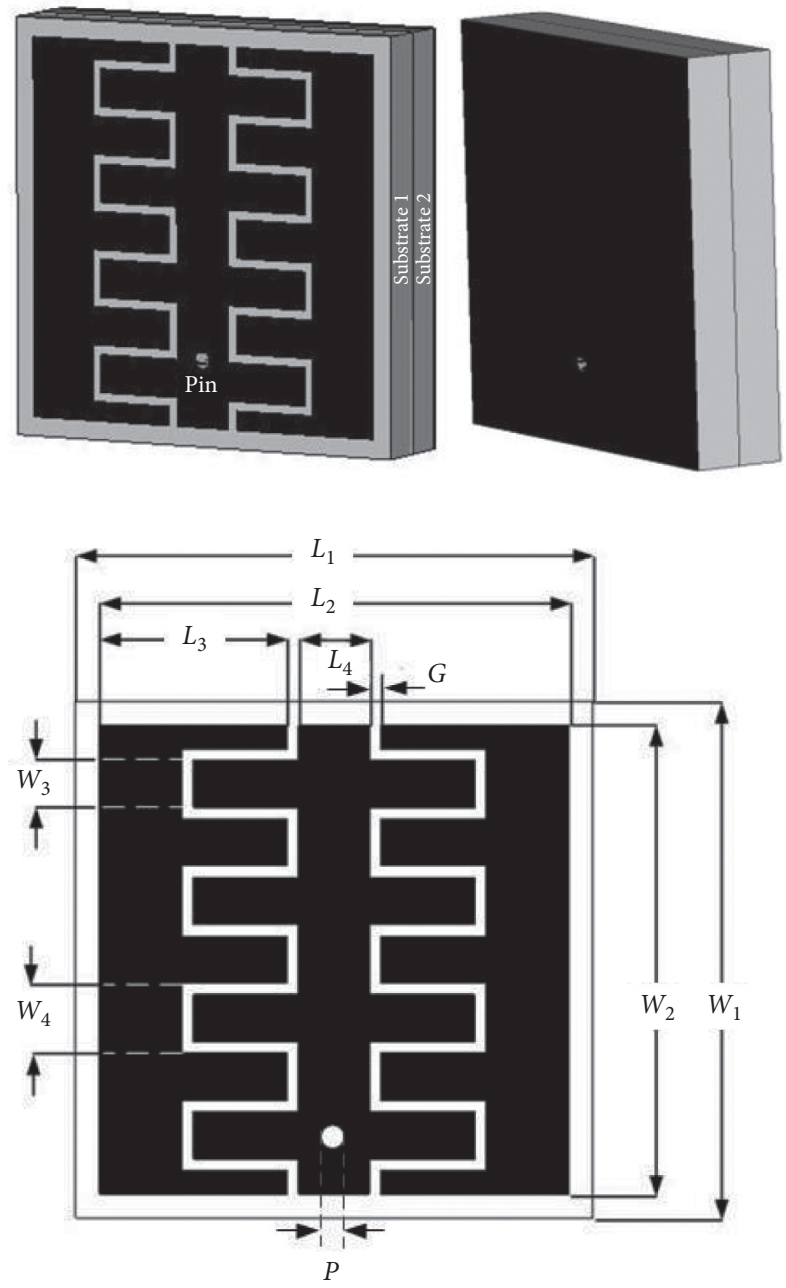

FIgURE 4: The geometry of ICPW-EBG unit cell.

2.2. Array of ICPW-EBG Unit Cells with Dipole. The $10 \times 10$ ICPW-EBG unit cells were arranged as an array with the gap between the unit cells of $1.8 \mathrm{~mm}$. The total area of the array is $181.80 \times 181.80 \mathrm{~mm}^{2}$ as shown in Figure 10 . This proposed array will be used as an antenna reflector, so the size of array must cover the antenna size. From simulation, it is found that the $E$ field is parallel along the $Y$ axis of the interdigital structure. The current density passes through the band gap at 1.8 GHz, 2.45 GHz, and $3.7 \mathrm{GHz}$, as shown in Figure 11. It does not affect the ICPW structure, so it can be used as a reflector for the antenna with wave propagation at three desired frequencies. With small unit cell size, the array of $10 \times 10$ unit cells as a reflector is also very small. In addition, with surface wave suppression and in-phase plane-wave reflection, it can enhance the directivity of dipole antenna when applying with compact ICPW-EBG reflector, working as a high-gain directional antenna.

Then the dipole antenna is designed as the electromagnetic radiating source to be used with the ICPW-EBG reflector. It is designed from a copper pipe with $3.46 \mathrm{~mm}$ $\left(W_{1}\right)$ diameter and $0.46 \mathrm{~mm}(T)$ thickness. Figure 12 shows the dipole diagram and parameters designed at
TABLE 1: ICPW-EBG unit cell parameter and dimension.

\begin{tabular}{lc}
\hline Parameters & Dimension $(\mathrm{mm})$ \\
\hline$L_{1}$ & 18.00 \\
$L_{2}$ & 16.20 \\
$L_{3}$ & 6.48 \\
$L_{4}$ & 2.16 \\
$G$ & 0.54 \\
$W_{1}$ & 18.00 \\
$W_{2}$ & 16.20 \\
$W_{3}$ & 1.08 \\
$W_{4}$ & 2.16 \\
$P$ & 0.6 \\
\hline
\end{tabular}

three frequencies of $1.8 \mathrm{GHz}, 2.45 \mathrm{GHz}$, and $3.7 \mathrm{GHz}$. The antenna lengths of all dipoles at the three frequencies are $0.47 \lambda o$, with their sizes optimized, resulting in all dimensions in Table 2.

From the previous ICPW-EBG array and dipole antenna design, this section will present the simulation results of the dipole antenna with ICPW-EBG reflector in order to observe the performances of ICPW-EBG on the dipole antenna. The dipole antenna was placed above ICPW-EBG reflector acting 


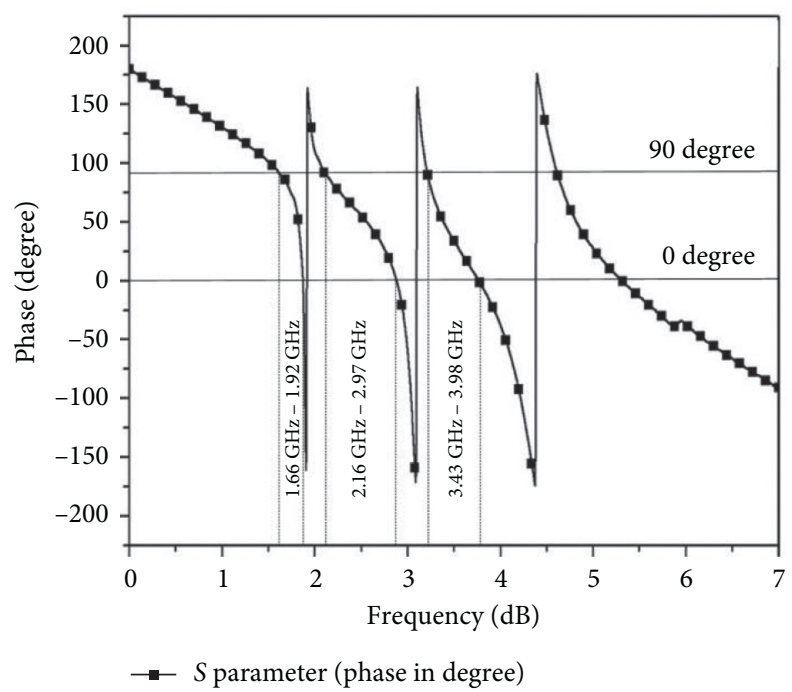

FIGURE 5: The simulation results phase diagram of ICPW-EBG unit cell.

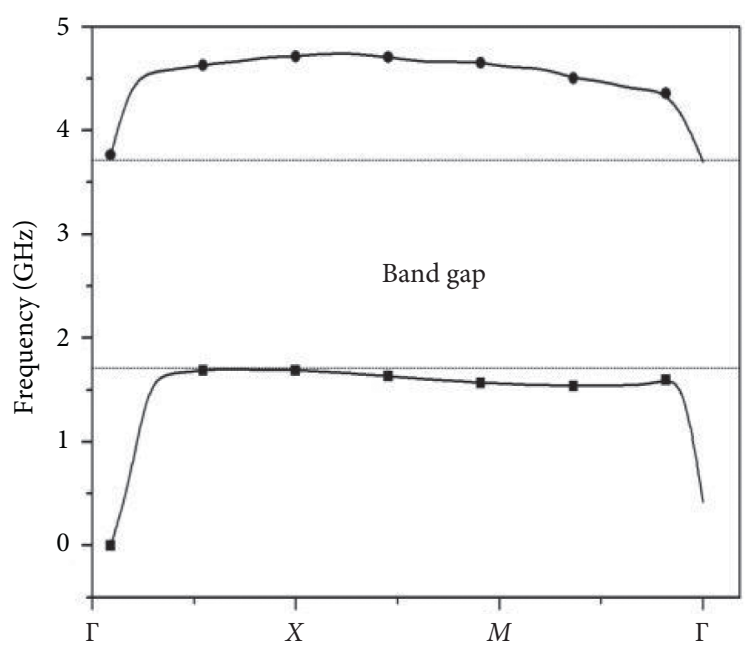

FIgURE 6: The simulation dispersion diagram result of ICPW-EBG unit cell.

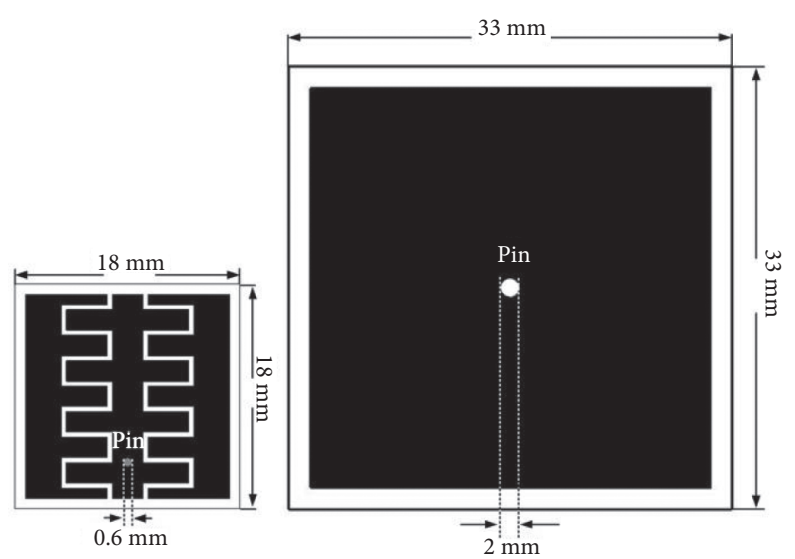

FIGURE 7: The dimension structure comparison between ICPW-EBG unit cell and M-EBG unit cell at $1.8 \mathrm{GHz}$. 

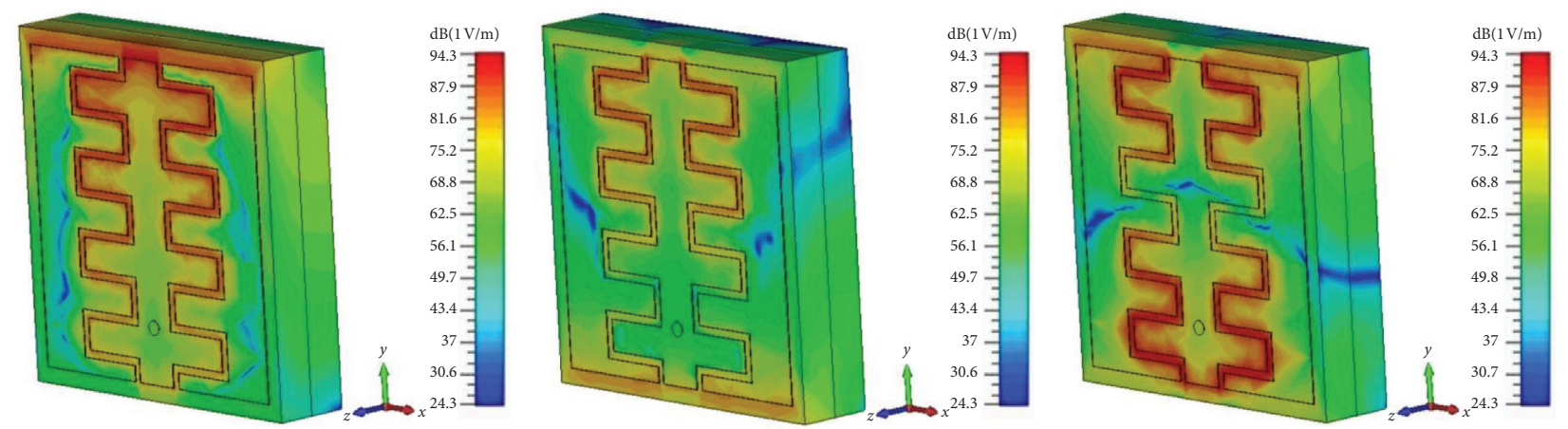

(a)
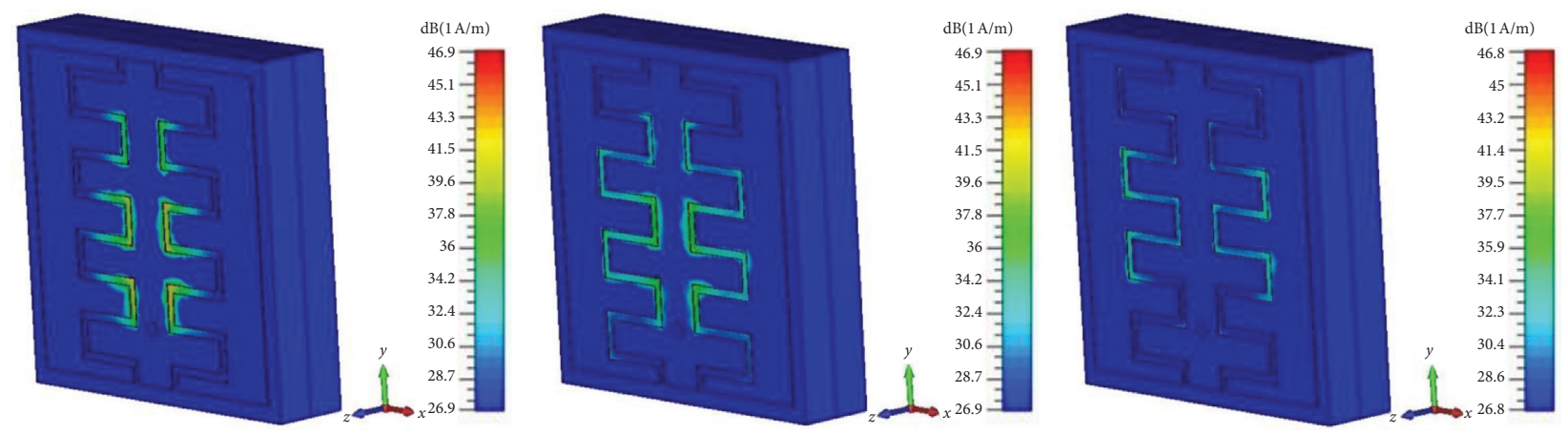

(b)

FIGURE 8: The simulation results of ICPW-EBG unit cell at $1.8 \mathrm{GHz}, 2.45 \mathrm{GHz}$, and $3.7 \mathrm{GHz}$. (a) Electric field results. (b) Magnetic field results.

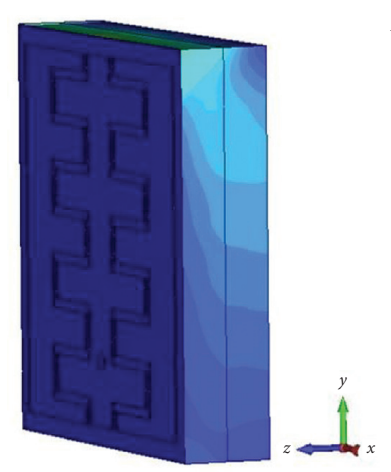

(a)

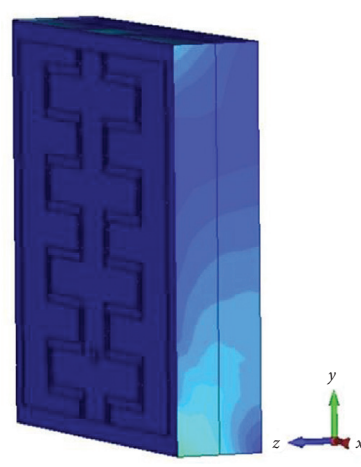

(b)
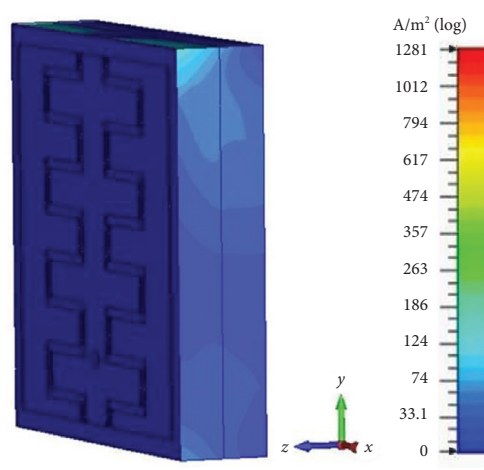

(c)

FIgURE 9: The current density simulation results of ICPW-EBG unit cell at (a) $1.8 \mathrm{GHz}$, (b) $2.45 \mathrm{GHz}$, and (c) $3.7 \mathrm{GHz}$.
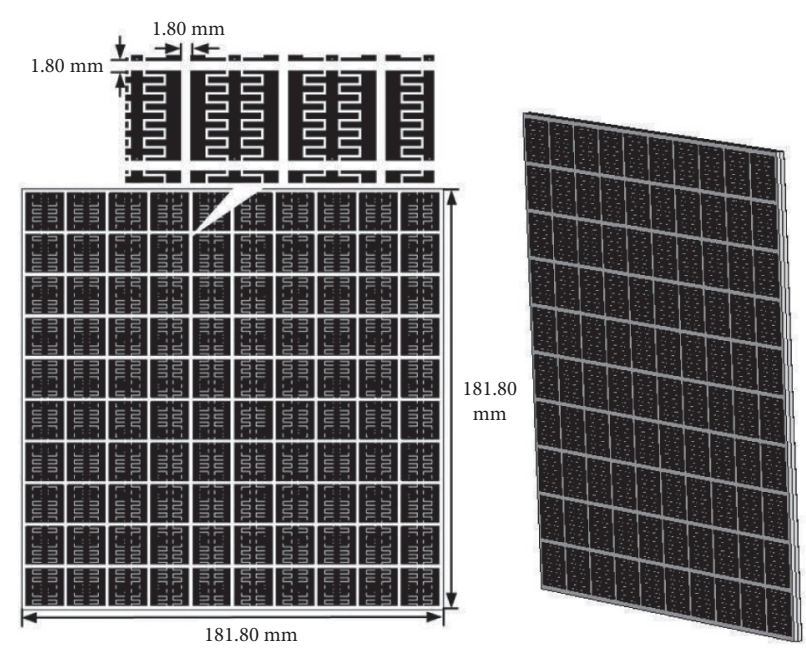

Figure 10: The structure and dimension of array $10 \times 10$ ICPW-EBG array. 

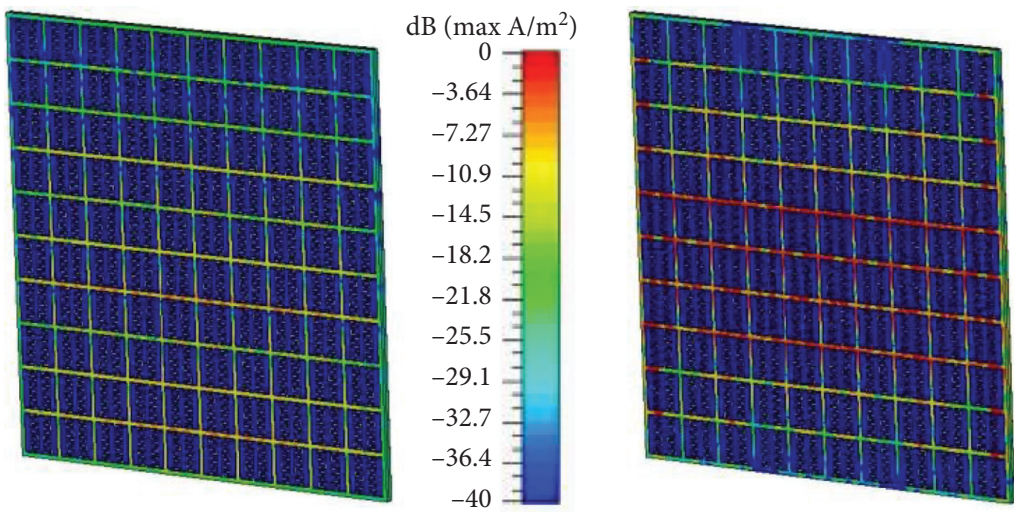

$\mathrm{dB}\left(\max \mathrm{A} / \mathrm{m}^{2}\right)$
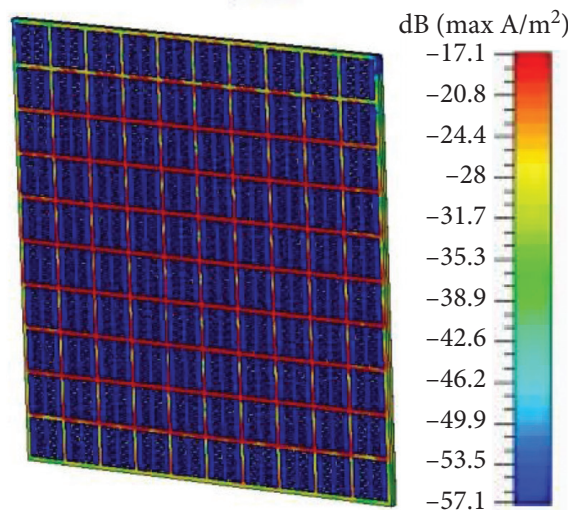

FIgURE 11: The current density simulation results of $10 \times 10 \mathrm{ICPW}-\mathrm{EBG}$ array at $1.8 \mathrm{GHz}, 2.45 \mathrm{GHz}$, and $3.7 \mathrm{GHz}$, respectively.

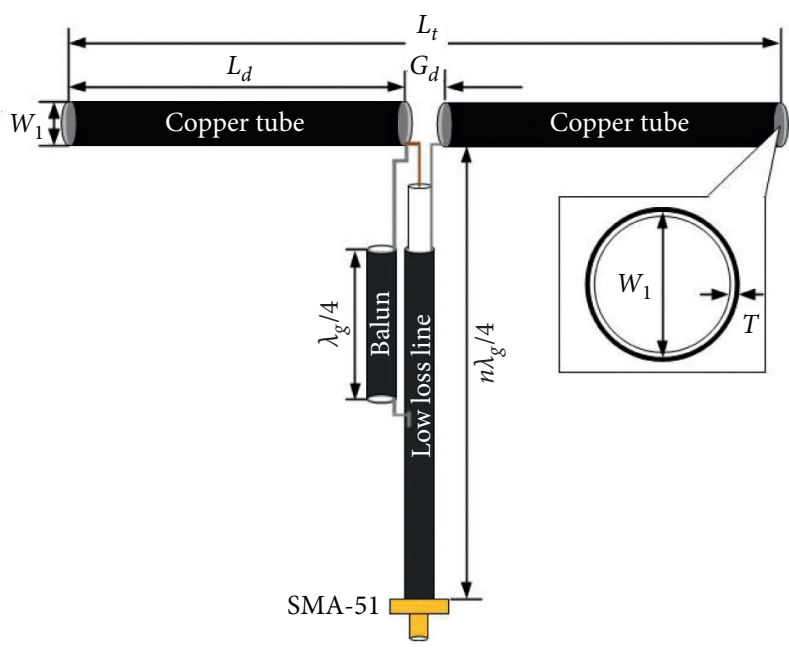

FIgURE 12: The geometry of dipole antenna.

TABle 2: Dipole antenna dimension.

\begin{tabular}{lccc}
\hline Dipole parameters & & Dimension $(\mathrm{mm})$ \\
$f=2.45 \mathrm{GHz}$ & $f=3.7 \mathrm{GHz}$ \\
\hline$L_{d}$ & $f=1.8 \mathrm{GHz}$ & 22.00 & 13.80 \\
$L_{t}$ & 32.50 & 47.00 & 29.60 \\
$G_{d}$ & 68.00 & 2.50 & 2.00 \\
$W_{1}$ & 3.00 & 3.46 & 3.46 \\
$T$ & 3.46 & 0.46 & 0.46 \\
\hline
\end{tabular}



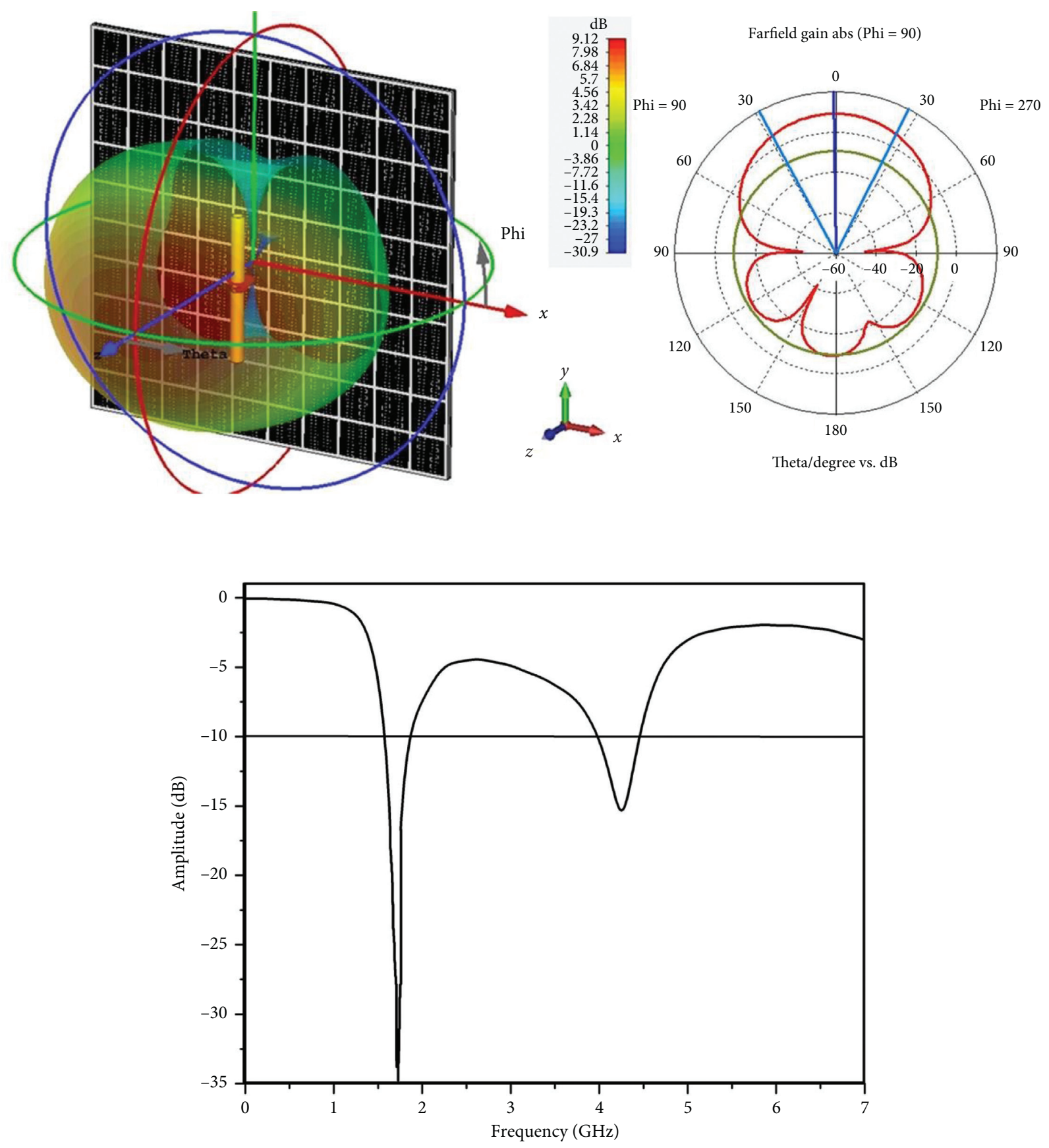

— $1.8 \mathrm{GHz}$ S- parameters

(a)

FIgURE 13: Continued. 

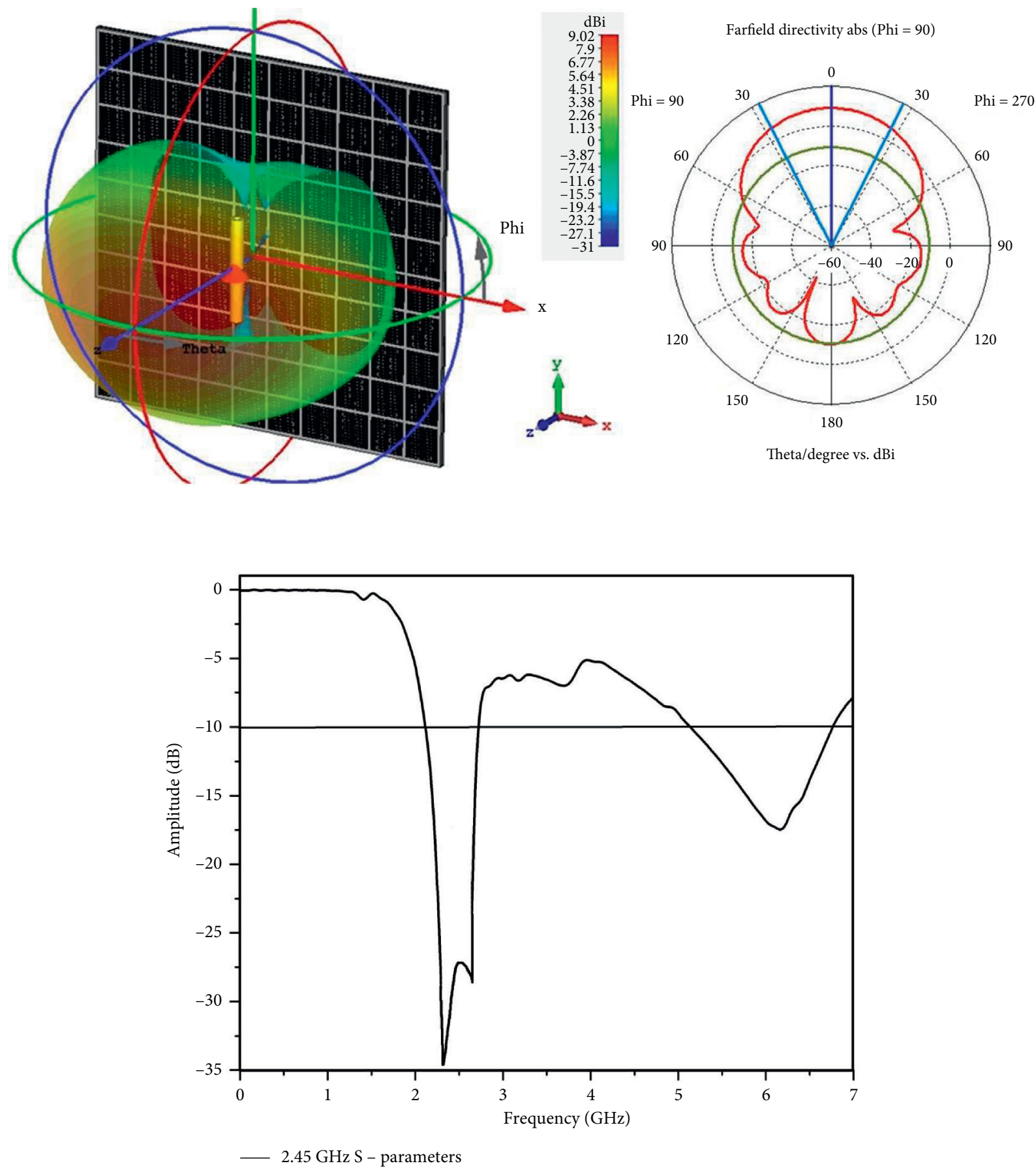

(b)

FIgURE 13: Continued. 

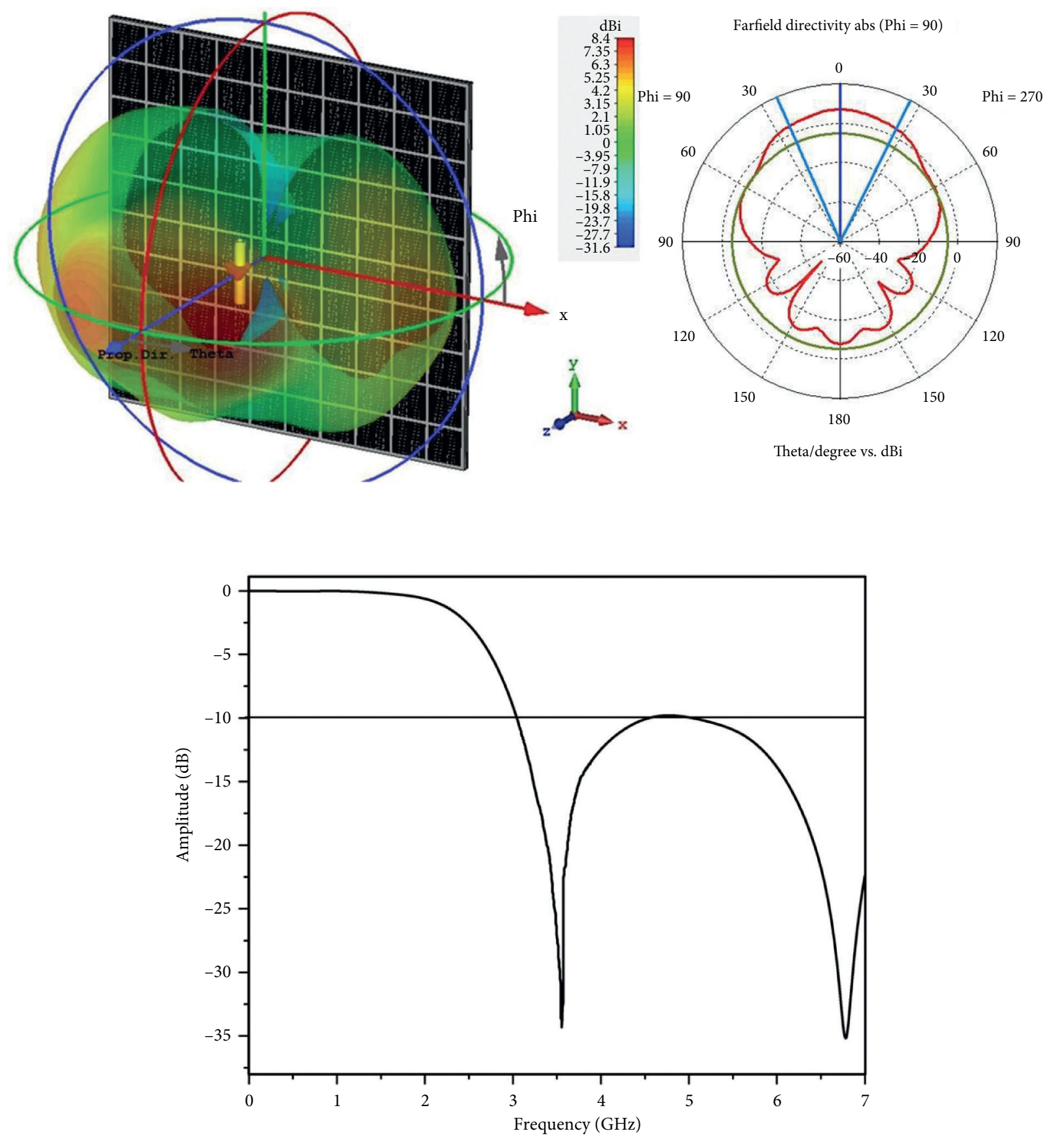

- $3.7 \mathrm{GHzS}$ - parameters

(c)

FIGURE 13: The simulation radiation pattern and insertion loss of dipole antenna within ICPW-EBG reflector: (a) $1.8 \mathrm{GHz}$, (b) $2.45 \mathrm{GHz}$, and (c) $3.7 \mathrm{GHz}$.

as an electromagnetic source radiating to the reflector. By adjusting the distance between the antenna and the reflector, the distance of about $\lambda / 8$ results in the phase difference between antenna and reflector of about 0 degree because the ICPW-EBG reflector has a characteristic of an artificial magnetic conductor. In this case, the dipole is aligned along the $y$ axis because the current line direction and E-field plane conform to that direction. Because the capacitive value has a significant impact on the E-field, it can increase the highest antenna gain. Also, the in-phase between the antenna and reflector makes the maximum gain at the designed frequency. The simulation results of the proposed structure of the dipole antenna and the ICPW-EBG reflector at all frequencies are shown in Figures 13(a)-13(c). At frequency of $1.8 \mathrm{GHz}$, the distance of $\lambda / 8$ is about $20.81 \mathrm{~mm}$, the simulation results show that the resonance frequency is shifted to 


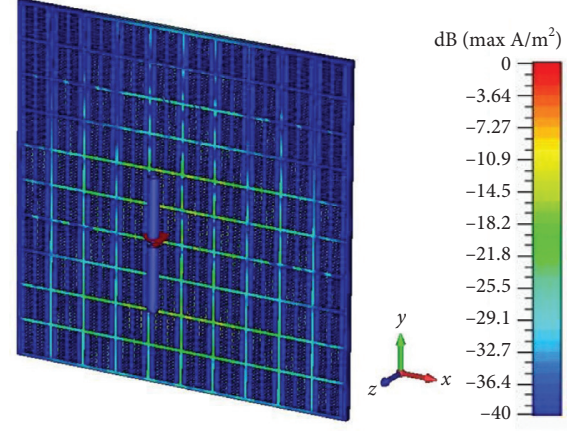

(a)

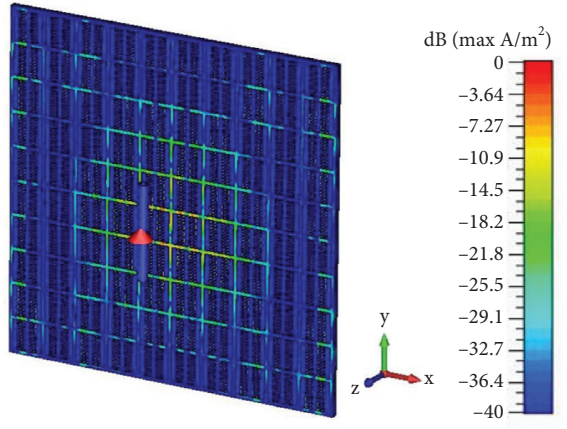

(b)

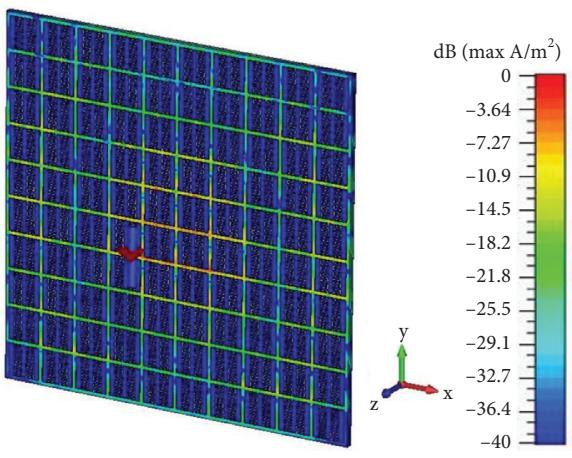

(c)

FIGURE 14: The simulation current density results of dipole antenna effect on ICPW-EBG reflector: (a) $1.8 \mathrm{GHz}$, (b) $2.45 \mathrm{GHz}$, and (c) $3.7 \mathrm{GHz}$.
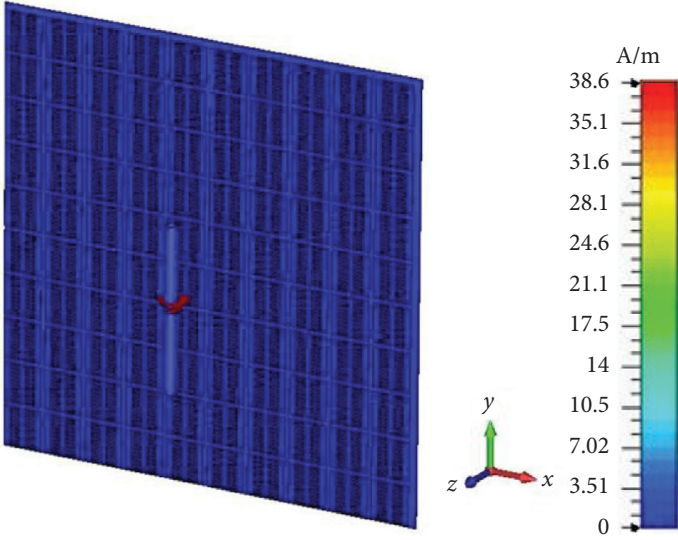

(a)
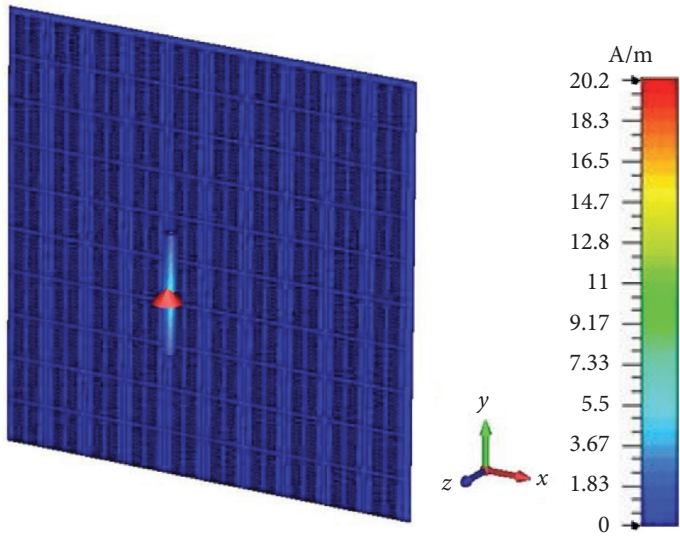

(b)

FIgURE 15: Continued. 


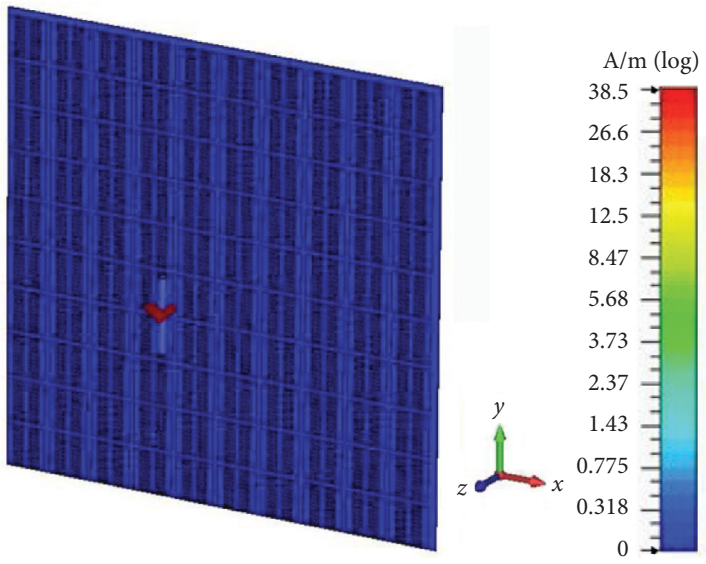

(c)

FIGURE 15: The simulation surface current results of dipole antenna within ICPW-EBG reflector: (a) $1.8 \mathrm{GHz}$, (b) $2.45 \mathrm{GHz}$, and (c) $3.7 \mathrm{GHz}$.

TABLE 3: Comparison of the presented antenna with reference EBG unit cell and antennas.

\begin{tabular}{|c|c|c|c|c|c|c|c|}
\hline $\begin{array}{l}\text { Reference } \\
\text { number }\end{array}$ & $\begin{array}{c}\text { No. of bands (structure } \\
\text { shaped) }\end{array}$ & Freq.(GHz) & $\begin{array}{l}\text { Unit cell size } \\
\left(\mathrm{mm}^{3}\right)\end{array}$ & Overall size $\left(\mathrm{mm}^{3}\right)$ & $\begin{array}{l}\text { No. of unit } \\
\text { cell array }\end{array}$ & IBW (\%) & $\begin{array}{l}\text { Measurement } \\
\text { gain }(\mathrm{dB})\end{array}$ \\
\hline \multirow{3}{*}{ [11] } & $1($ fractal $)$ & 11.35 & $11 \times 11 \times 1.6$ & $77 \times 77 \times 1.6$ & \multirow{3}{*}{$7 \times 7$} & 7.3 & - \\
\hline & 1 (fork like) & 11.5 & $16 \times 16 \times 1.6$ & $112 \times 112 \times 1.6$ & & 7.0 & \\
\hline & 1 (spiral) & 1.95 & $10 \times 10 \times 1.6$ & $70 \times 70 \times 1.6$ & & 0.3 & \\
\hline [12] & 1(ID-UC) & 2.35 & $7.3 \times 7.3 \times 1.5$ & $14.6 \times 36.5 \times 1.5$ & $2 \times 5$ & 46 & - \\
\hline \multirow{6}{*}[13]{} & 3 (double slotted) & $2.42-2.95$ & $5 \times 5 \times 2.74$ & $15 \times 15 \times 2.74$ & $3 \times 3$ & 19.70 & \\
\hline & \multirow{5}{*}{3 (triple side slotted) } & $5.82-6.30$ & \multirow{5}{*}{$5 \times 5 \times 2.74$} & \multirow{5}{*}{$15 \times 15 \times 2.74$} & \multirow{5}{*}{$3 \times 3$} & 7.80 & \\
\hline & & $8.27-9.28$ & & & & 6.20 & \\
\hline & & $4.29-4.65$ & & & & 8.00 & \\
\hline & & $5.56-6.28$ & & & & 10.38 & \\
\hline & & $7.90-7.94$ & & & & 4.30 & \\
\hline \multirow{2}{*}[16]{} & \multirow{2}{*}{2 (slot ant. fed by CPW) } & $2.50-5.30$ & \multirow{2}{*}{$76 \times 61 \times 0.508$} & \multirow{2}{*}{$76 \times 93 \times 0.508$} & \multirow{2}{*}{1} & 78.95 & - \\
\hline & & $13.5-16.3$ & & & & 18.79 & - \\
\hline [20] & $\begin{array}{l}1 \text { (interdigital and } \\
\text { inductive strip) }\end{array}$ & $2.44-2.51$ & $7 \times 8.1 \times 4.3$ & $28.3 \times 44.8 \times 4.3$ & $3 \times 4$ & 3.04 & 7.0 \\
\hline \multirow{4}{*}[23]{} & \multirow{4}{*}{$\begin{array}{l}4 \text { (slot ant. with spiral } \\
\text { stub and interdigital } \\
\text { CPW feed) }\end{array}$} & $1.72-2.0$ & \multirow{4}{*}{$23.25 \times 27.5 \times 1.6$} & \multirow{4}{*}{$23.25 \times 40 \times 1.6$} & \multirow{4}{*}{1} & 15.04 & 1.92 \\
\hline & & $2.34-2.63$ & & & & 11.66 & 2.03 \\
\hline & & $3.54-3.95$ & & & & 10.94 & 2.16 \\
\hline & & $5.10-5.32$ & & & & 4.21 & 2.36 \\
\hline [25] & $\begin{array}{l}1 \text { (interdigital cap. } \\
\text { loaded slot) }\end{array}$ & 2.45 & $16.3 \times 3.9$ & $16.3 \times 3.9$ & 1 & 18.7 & 2.075 \\
\hline [29] & $\begin{array}{c}\text { (square patch AMC } \\
\text { substrate and PRS } \\
\text { superstrate) }\end{array}$ & 14.0 & $4.5 \times 4.5 \times 1.13$ & $150 \times 150 \times 11.3$ & $32 \times 32$ & $>30$ & 19.0 \\
\hline \multirow{2}{*}[30]{} & \multirow{2}{*}{$\begin{array}{l}2 \text { (EBG with circular } \\
\text { slot) }\end{array}$} & $3.53-3.87$ & \multirow{2}{*}{$4.8 \times 3.0 \times 1.27$} & \multirow{2}{*}{$33 \times 21 \times 1.27$} & \multirow{2}{*}{$4 \times 6$} & 8.9 & 6.71 \\
\hline & & $4.35-4.69$ & & & & 7.52 & 4.58 \\
\hline \multirow{2}{*}{$\begin{array}{l}\text { ICPW-EBG } \\
\text { proposed }\end{array}$} & \multirow[b]{2}{*}{$3(\mathrm{ICPW})$} & 1.82 .45 & \multirow[b]{2}{*}{$18 \times 18 \times 3.2$} & \multirow[b]{2}{*}{$181.8 \times 181.8 \times 24.2$} & \multirow[b]{2}{*}{$10 \times 10$} & 40.64 & \multirow[b]{2}{*}{8.728 .568 .10} \\
\hline & & 3.7 & & & & $\begin{array}{l}30.72 \\
43.82\end{array}$ & \\
\hline
\end{tabular}

$1.722 \mathrm{GHz}$, the $-10 \mathrm{~dB}$ bandwidth is $287.0 \mathrm{MHz}$ $(1.622-1.909 \mathrm{GHz})$, and directivity is $9.12 \mathrm{~dB}$. At frequency of $2.45 \mathrm{GHz}$, the distance of $\lambda / 8$ is about $15.30 \mathrm{~mm}$, the simulation results show that the resonance frequency is shifted to $2.317 \mathrm{GHz}$, the $-10 \mathrm{~dB}$ bandwidth is $8,667.0 \mathrm{MHz}$ $(2.252-3.1187 \mathrm{GHz})$, and the directivity is $9.02 \mathrm{~dB}$. At frequency of $3.78 \mathrm{GHz}$, the distance of $\lambda / 8$ is about $10.13 \mathrm{~mm}$, the $-10 \mathrm{~dB}$ bandwidth is $1,060.0 \mathrm{MHz}(2.891-3.9512 \mathrm{GHz})$, 

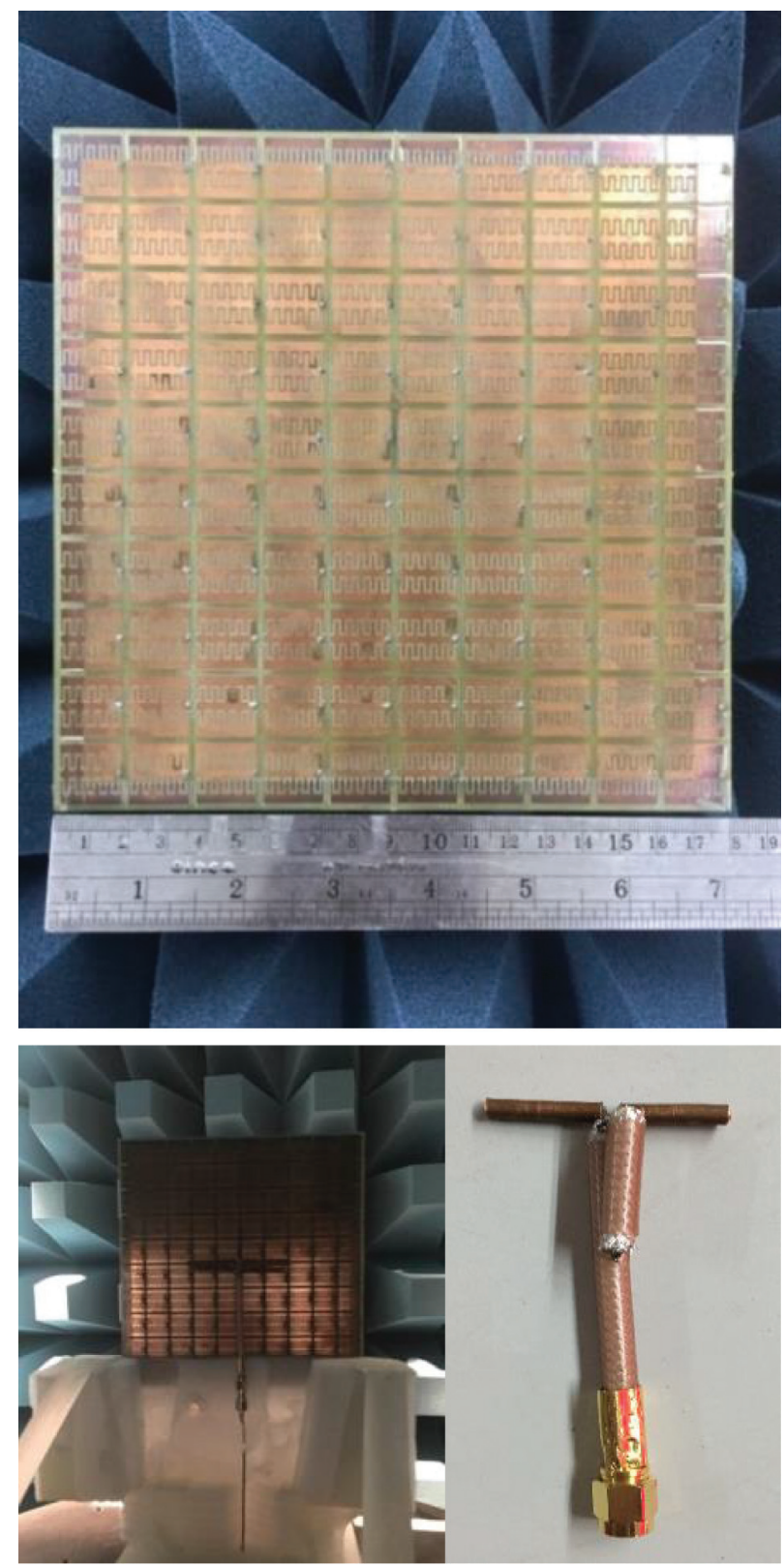

FIGURE 16: The created geometry of ICPW-EBG reflector and dipole antenna on the antenna gain measurement.

and the directivity is $8.4 \mathrm{~dB}$. Although the resonance frequencies are shifted, the frequency bandwidths still cover the usable frequency bands.

The simulated current densities of dipole antenna affecting ICPW-EBG reflector are shown in Figures 14(a)-14(c). It was found that the current density flows in the gap between ICPWEBG unit cell, but does not have current flow on the structure of ICPW-EBG unit cell. At the resonant frequency, it has a strong current density, which can be explained that when applying ICPW-EBG unit cell with an antenna, ICPW-EBG rejects the surface wave and has only the propagation wave that is complement to the propagation wave of the antenna.

This causes the antenna to have a higher directivity. Figures 15(a)-15(c) show simulation results of the observed surface current responses. It is found that at all frequencies there is no surface current. It is clearly seen that ICPW-EBG can eliminate the surface wave to be just an extra propagation wave to the antenna.

From the simulation results of ICPW-EBG reflector driven with dipole antennas, the ICPW-EBG structure can increase directivity of the dipole antennas and perform with directional pattern. The antenna directivities are improved to be $9.12 \mathrm{~dB}$ at $1.8 \mathrm{GHz}, 9.02 \mathrm{~dB}$ at $2.45 \mathrm{GHz}$, and $8.40 \mathrm{~dB}$ at $3.7 \mathrm{GHz}$. The distance between antenna and reflector is reduced from $\lambda / 4$ to $\lambda / 8$. The ICPW-EBG can control the responses for three frequency bands. With small ICPW-EBG unit cell dimension of $\lambda / 4$, arranging the ICPW-EBG with $10 \times 10$ cells makes the overall size of the ICPW-EBG reflector 


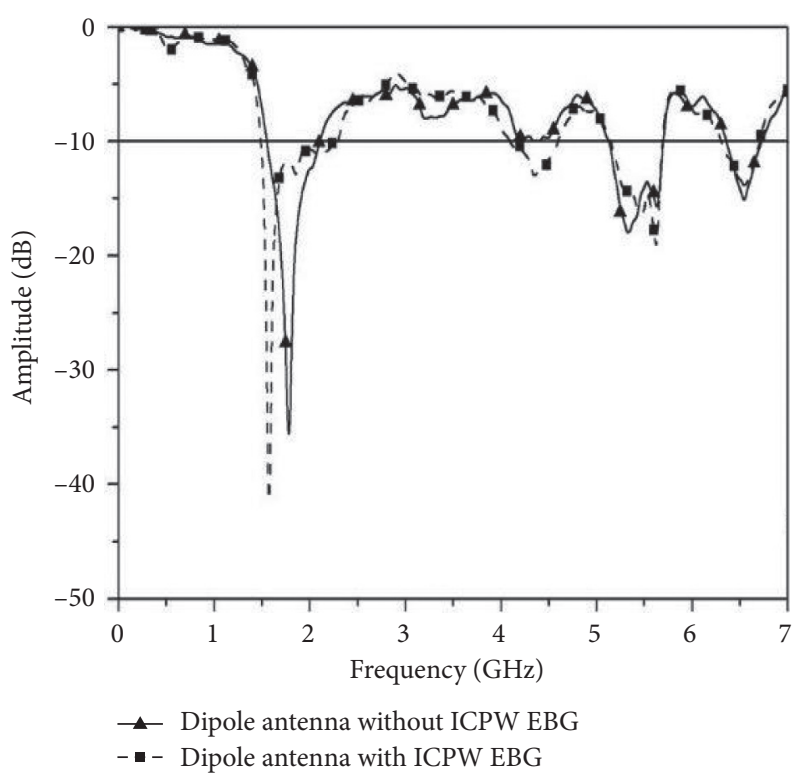

(a)

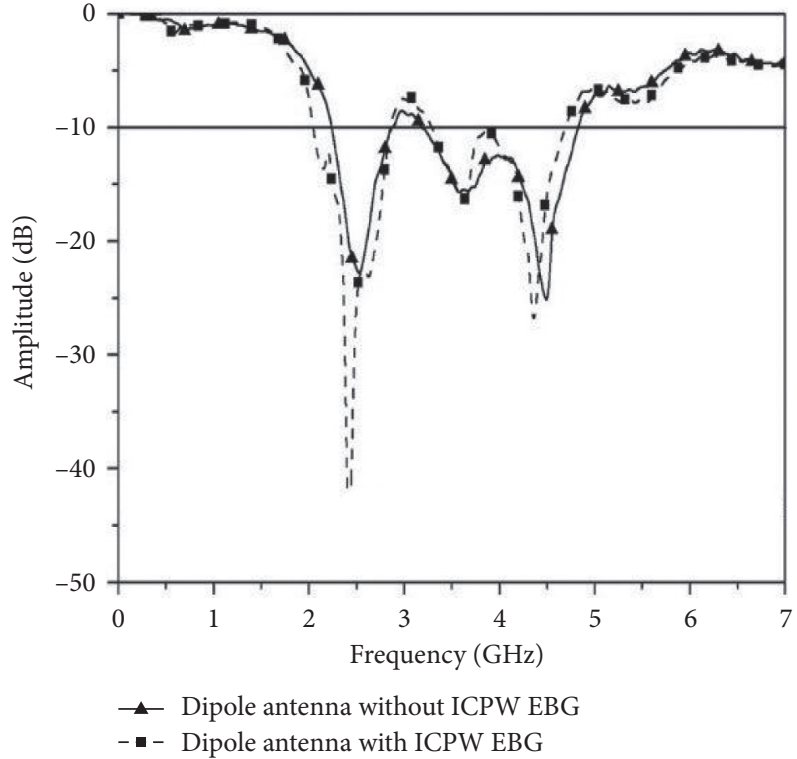

(b)

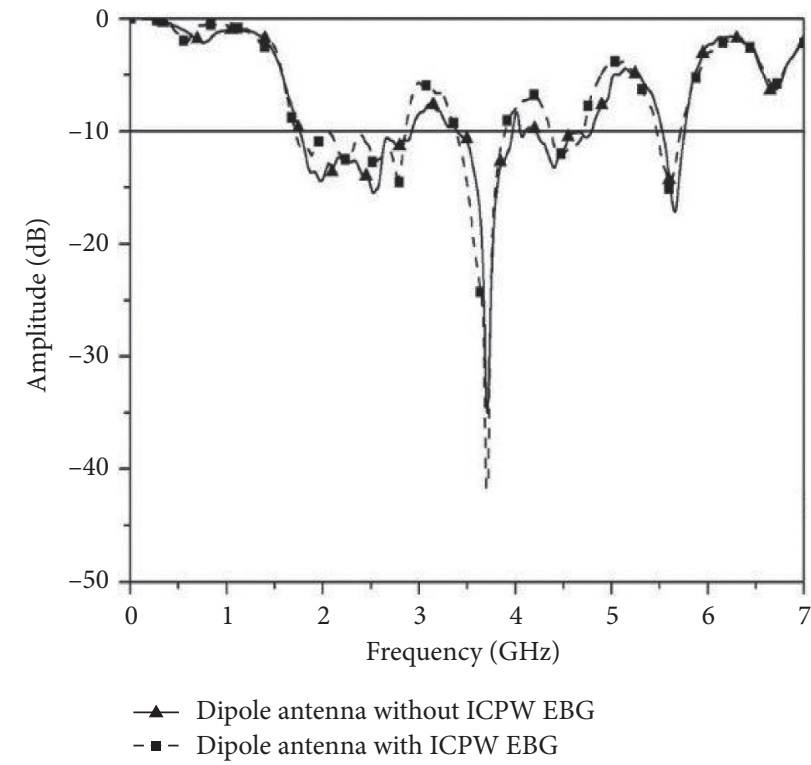

(c)

Figure 17: The S11 measurement results of dipole antenna with ICPW-EBG: (a) $1.8 \mathrm{GHz}$, (b) $2.45 \mathrm{GHz}$, and (c) $3.7 \mathrm{GHz}$.

very compact. In conclusion, ICPW-EBG is simple and compact in structure and easy to design. In Table 3, the performance of the proposed ICPW-EBG antenna is compared with unit cell design and antenna design with the previous reference. The results of the measurement will be presented in the next section.

\section{Measurement Results}

In this part, the measurement of return losses and radiation patterns will be performed at three resonance frequencies. The structure of the proposed antenna was implemented as shown in Figure 16. For only dipole antenna, the measured bandwidths (higher $10 \mathrm{~dB}$ return loss) of $550 \mathrm{MHz}(1.6-2.15 \mathrm{GHz})$ at $1.8 \mathrm{GHz}, \quad 530 \mathrm{MHz}(2.25-2.78 \mathrm{GHz})$ at $2.45 \mathrm{GHz}$, and $620 \mathrm{MHz}(3.33-3.95 \mathrm{GHz})$ at $3.7 \mathrm{GHz}$ were found. For the dipole with the proposed ICPW-EBG reflector, the measured bandwidths of $760 \mathrm{MHz}(1.49-2.25 \mathrm{GHz})$ at $1.8 \mathrm{GHz}, 750 \mathrm{MHz}$ $(2.10-2.85 \mathrm{GHz})$ at $2.45 \mathrm{GHz}$, and $710 \mathrm{MHz}(3.24-3.95 \mathrm{GHz})$ at $3.7 \mathrm{GHz}$ were found. The measured results are shown in Figure 17. In addition, the measurement of radiation patterns was done as the results are shown in Figure 18. It is found that the antenna has directional radiation, where the antenna gains at the $1.8 \mathrm{GHz}, 2.45 \mathrm{GHz}$, and $3.7 \mathrm{GHz}$ frequencies are $8.72 \mathrm{~dB}$, $8.56 \mathrm{~dB}$, and $8.1 \mathrm{~dB}$, respectively. It can be seen that the gains of the proposed antenna are higher compared with the dipole with PEC reflector. Also, the measured results agree very well with simulation results. 

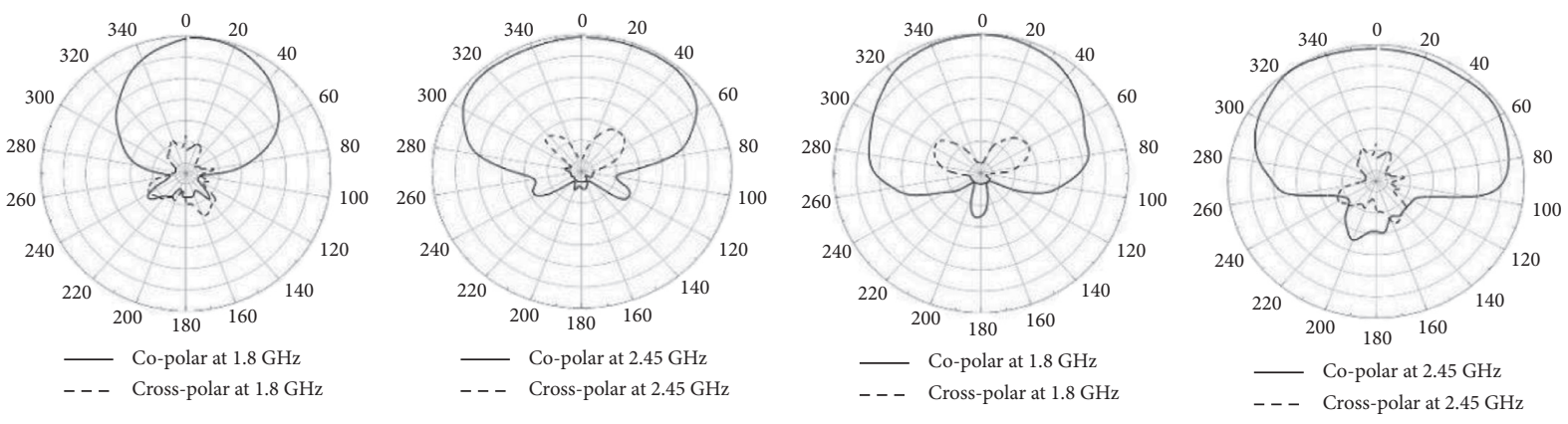

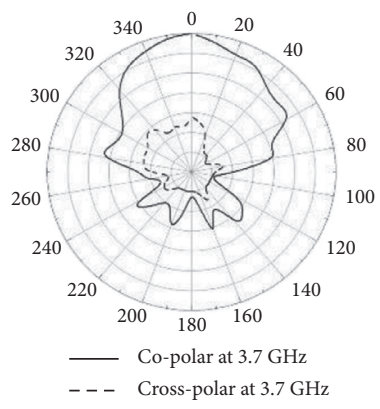

(a)

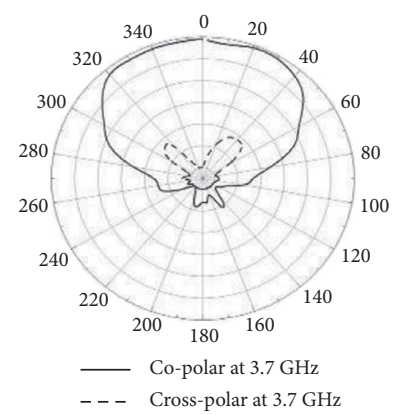

(b)

Figure 18: The radiation pattern measurement results. (a) E-plane at $1.8 \mathrm{GHz} 2.45 \mathrm{GHz}$ and $3.7 \mathrm{GHz}$. (b) $\mathrm{H}$-plane at $1.8 \mathrm{GHz} 2.45 \mathrm{GHz}$ and $3.7 \mathrm{GHz}$.

\section{Conclusion}

The new EBG unit cell with ICPW structure was proposed. The slow wave effect on the proposed structure could reduce the size of unit cell from $\lambda / 2$ to $\lambda / 4$ and can control the second and third resonance responses. The array of ICPWEBG unit cells was formed with the dimension $181.8 \times 181.8 \mathrm{~mm}$. Moreover, the distance between the dipole antenna and the ICPW-EBG reflector was reduced from the normal distance of $\lambda / 4$ to $\lambda / 8$, resulting in a low profile system. In addition, the ICPW-EBG reflector could increase the antenna gain at the frequencies $1.8 \mathrm{GHz}, 2.45 \mathrm{GHz}$, and $3.7 \mathrm{GHz}$ to be $8.72 \mathrm{~dB}, 8.56 \mathrm{~dB}$, and $8.1 \mathrm{~dB}$, respectively. The radiation patterns at three frequencies are directional. Also, the measured bandwidths of the proposed antenna were $760 \mathrm{MHz}, 750 \mathrm{MHz}$, and $710 \mathrm{MHz}$ at $1.8 \mathrm{GHz}, 2.45 \mathrm{GHz}$, and 3.7 $\mathrm{GHz}$ frequency bands, respectively.

\section{Data Availability}

The data used to support the findings of this study are included within the article.

\section{Conflicts of Interest}

The authors declare that they have no conflicts of interest.

\section{Acknowledgments}

This work was partially supported by the Thailand Research Fund under the grant number RTA6080008 and The fund by King Mongkut's University of Technology North Bangkok contract no. KMUTNB-61-GOV-B-42, and National Astronomical Research Institute of Thailand (NARIT).

\section{References}

[1] V. G. Veselago, "The electrodynamics of substances with simultaneously negative values of lepsilon and $\mu$," Soviet Physics Uspekhi, vol. 10, no. 4, pp. 509-514, 1968.

[2] E. Brundermann, H.-W. Hubers, and M. F. Kimmitt, "Optical components," in Terahertz Techniquesp. 94, Springer Series in Optical Sciences, Newyork, NY, USA, 2012.

[3] G. V. Eleftheriades and K. G. Balmain, "Microwave devices and antennas using negative-refractive-index transmissionline metamaterials," in Negative-refraction Metamaterials, Fundamental Principles and Applications, pp. 53-88, John Wiley \& Sons, Inc., Toronto, Canada, 2005.

[4] D. B. Brito, Metamaterial Inspired Improved Antennas and Circuits, pp. 15-92, Universidade Federal Do Rio Grande Do Norte Telecom Paristech, Natal,Brazil, 2010.

[5] N. E. Richard and W. Ziolkowski, Metamaterials Physics and Engineering Explorations, pp. xv-xvi, John Wiley \& Sons, Inc., Toronto, Canada, 2006.

[6] F. Yang and Y. Rahmat-Samii, Low Profile Wire Antennas on EBG Ground Plane in Electromagnetic Band Gap Structures in Antenna Engineering, pp. 164-169, Cambridge University Press, New York, NY, USA, 2009.

[7] A. Kaabal et al., "Design of EBG antenna with multi-sources excitation for high directivity applications," in Proceedings of the 11th International Conference Interdisciplinarity in Engineering, Inter-Eng. 2017, pp. 598-604, Tirgu-Mures, Romania, October 2017.

[8] S. Palreddy, "Wideband electromagnetic band gap (EBG) structures, analysis and applications to antenna," $\mathrm{Ph}$. D. dissertation, Department Electron. Engineering, Virginia 
Polytechnic Institute and State University, Blacksburg, VA, USA, 2015.

[9] O. Ayop et al., "Comparative study of different shape of periodic patch electromagnetic band gap structure for planar antenna application," in Proceedings of the IndonesiaMalaysia Microwave Antenna Conference (IMMAC2010), pp. 1-4, Bandung, Indonesia, June 2010.

[10] L. Li et al., "Surface-wave suppression band gap and planewave reflection phase band of mushroom-like photonic band gap structures," Journal of Applied Physics, vol. 130, no. 2, pp. $1-8,2008$.

[11] S. Chauhan and P. K. Singhal, "Comparative analysis of different types of planer EBG structures," International Journal of Scientific and Research Publications, vol. 4, no. 6, pp. 1-5, 2014.

[12] B.-Q. Lin and X. Wen, "A novel uniplanar compact EBG incorporated with interdigital structure," Microwave and Optical Technology Letters, vol. 50, no. 3, pp. 555-557, March 2008.

[13] M. K. Abdulhameed et al., "Novel design of triple-band EBG," Telkomnika, vol. 17, no. 4, pp. 1682-4691, 2019.

[14] A. Venkateswaran, "Analysis of planar EBG structures using transmission line models," M. S. thesis, Department of Electronics and Computer Engineering, McGill University, Montreal, Canada, 2009.

[15] J. M. Laheurte, Compact Antennas for Wireless Communications and Terminals: Theory and Design, pp. 1-2, WileyISTE, San Antonio, TX, USA, 2012.

[16] P. Kurgan, A. Bekasiewicz, and M. Kitlinski, "Filtering EBG structures implemented in coplanar waveguide feed line of planar slot antenna," in Proceedings of the 6th European Conference on Antennas and Propagation (EUCAP), pp. 2845-2848, Prague, Czech Republic, March 2012.

[17] M. E. de Cos and F. Las-Heras, "Dual-band uniplanar CPWfed monopole/EBG combination with bandwidth enhancement," IEEE Antennas and Wireless Propagation Letters, vol. 11, pp. 365-368, 2012.

[18] J. Coonrod, "Comparing micostrip and CPW performance," Microwave Journal, vol. 55, no. 7, pp. 74-82, 2012.

[19] M. S. Kanitk and S. B. Deosarkar, "Design of reconfigurable antenna using MSF-EBG structure to improve performance parameters," IETE Journal of Research, 2019.

[20] J. Zeng, "Compact electromagnetic band-gap structures (EBG) and its applications in antenna systems," M. S. thesis, Department of Electrical and Computer Engineering, Waterloo University, Ontario, Canada, 2013.

[21] M. Joodaki and M. Rezaee, "Coplanar waveguide (CPW) loaded with electromagnetic band gap (EBG) structure modeling and application to displacement sensor," IEEE Sensors Journal, vol. 16, no. 9, 2016.

[22] R. S. Beeresha, A. M. Khan, and R. H. V. Manjunath, "Design and optimization of interdigital capacitor," in Proceedings of the ICRIET-2016, pp. 73-78, Osaka, Japan, November 2016.

[23] T. Archevapanich, P. Chomtong, and P. Akkaraekthalin, "A quad-band slot antenna with spiral stub and interdigital CPW feed," in Proceedings of the 12th International Conference on Computer and Electrical Engineering, pp. 1-6, Delft, Netherlands, November 2019.

[24] T. Zhou, Y. Cao, and Z. Cheng, "Compact multiband interdigital-coupled-fed planar antenna with stepped-impedance structure for mobile handsets," Hindawi, International Journal Ot Antennas and Propagation, vol. 2017, Article ID 7435834, 2017.
[25] W. Cheng et al., "An interdigital capacitor load slot antenna with compact size," Progress in Electromagnetics Research Letters, vol. 64, pp. 15-19, 2016.

[26] S. Meesomklin, P. Chomtong, and P. Akkaraekthalin, "A compact multiband BPF using step-impedance resonators with interdigital capacitors," Radioengineering, vol. 25, no. 2, pp. 258-267, 2016.

[27] F. Xu, L. Li, K. Wu, S. Delprat, and M. Chaker, "Parameter extraction of interdigital slow-wave coplanar waveguide circuits using finite difference frequency domain algorithm," International Journal of $R F$ and Microwave Computer-Aided Engineering, vol. 18, no. 3, pp. 250-259, 2008.

[28] F. Xu et al., "Application of FDFD algorithm combine with shift and invert arnoldi technique in bilateral interdigital coplanar waveguide slow wave structure," in Proceedings of the IEEE MTT-S International Microwave Symposium Digest, pp. 1025-1028, San Francisco, CA, USA, June 2006.

[29] A. P. Feresidis et al., "Artificial magnetic conductor surfaces and their application to low-profile high-gain planar antennas," IEEE Transactions on Antennas and Propagation, vol. 53, no. 1, pp. 209-215, 2005.

[30] M. El Ghabzouri, A. E. Salhi, P. Anacleto, and P. Mendes, "Enhanced low profile, dual-band antenna via novel electromagnetic band gap structure," Progress in Electromagnetics Research C, vol. 71, pp. 79-89, 2017.

[31] L. Korowajczuk, LTE, WIMAX and WLAN Network Design Optimization and Performance Analysis, pp. 559-600, John Wiley \& Sons, Inc., Toronto, Canada, 2011. 